\title{
Oxyphil cells in thyroid disease: a uniform change?
}

\author{
CH KENDALL, EVA McCLUSKEY, JNAYLOR, MEAGLES
}

From the Department of Pathology, Clinical Sciences Building, Leicester Royal Infirmary, Leicester

SUMMARY Neoplastic and non-neoplastic oxyphil cells in thyroid disorders were investigated for $\vec{\circ}$ enzyme and synthetic activity, ultrastructural features, and immune complex deposition.

A reduced but definite content of thyroglobulin and similar enzyme profiles and ultrastructural $\stackrel{\omega}{S}$ features in all types of oxyphil change were found. Immune complex deposition was seen in Graves'용 disease and Hashimoto's thyroiditis but not in oxyphil neoplasms or colloid goitre with focal $\omega_{0}$ oxyphil change. The findings suggest that oxyphil cells do represent a uniform change. Immu- $\infty$ nological damage with immune complex deposition might be the cause of oxyphil change in only $\mathscr{\infty}_{\infty}$ some conditions.

Oxyphil change can occur in thyroid and certain other secretory glands. In thyroid oxyphil change is seen in various disorders, principally thyroiditis, colloid goitre, and as a focal or diffuse feature of some tumours. ${ }^{1}$ Although the fact that oxyphil cells are derived from follicular cells now seems to be accepted, ${ }^{2-4}$ the pathogenesis of the change and the nature of the cells remain unclear. Immunological damage to cells is postulated as the cause in some conditions such as Hashimoto's thyroiditis and Graves' disease. The early assumption that oxyphil cells were inactive was challenged when high activities of oxidative enzymes were shown. ${ }^{56}$ Differing views, however, have been expressed as to the capacity of oxyphil cells to synthesise thyroglobulin and thyroid hormones. ${ }^{4}$ Electron microscopy of oxyphil cells has shown large numbers of mitochondria, ${ }^{3}$ sometimes containing electron dense mitochondrial inclusions $(E D M I)^{2}$ and the variable presence of other features such as colloid droplets. There is also some uncertainty as to whether oxyphil change is uniform in different thyroid conditions or a heterogeneous change with a similar microscopic appearance.

We investigated oxyphil cells in various nonneoplastic and neoplastic disorders for enzymic and synthetic activity, ultrastructural features, and immune complex deposition in an attempt to explore further the nature of these cells and their pathogenesis.

\section{Material and methods}

Fresh thyroid tissue was obtained from thyroidectomy specimens. For histochemistry and

Accepted for publication 26 March 1986 immunofluorescence samples were quenched in isopentane and stored at $-70^{\circ} \mathrm{C}$. For electron microscopy diced $1 \mathrm{~mm}$ cubes of tissue were immersed in Karnovsky's fixative. Samples were also routinely $\vec{\oplus}$ paraffin processed after fixation in formol saline for up to 24 hours. Further tissue, similarly fixed and processed, was also obtained from the files of the Leicester Royal Infirmary.

\section{HISTOCHEMISTRY}

Three oxyphil adenomas and oxyphil areas in two $\overrightarrow{\overrightarrow{0}}$ examples of Graves' disease, two colloid goitres, one $\frac{3}{3}$ Hashimoto's thyroiditis, and one papillary thyroid carcinoma were used. Enzyme methods on frozen sec-o tions were performed as described by Lojda. ${ }^{8}$ The enzymes investigated were iso-citrate dehydrogenase? (ICDH), succinate dehydrogenase (SDH), nicotinamide adenosine dehydrogenase (NADH), $\beta$-hydroxybutyrate dehydrogenase (HBDH), cyto- $O$ chrome oxidase (Cyto ox), glycerol-3-phosphate dehydrogenase (GL3PDH), and glutamate dehy-은 drogenase (GDH).

\section{IMMUNOPEROXIDASE}

The material comprised four oxyphil adenomas, two oxyphil carcinomas, and two examples of Hashimoto's thyroiditis. Paraffin sections were dewaxed, $\omega$ rehydrated to phosphate buffered saline, and endogenous peroxidase was blocked with methanol in hydrogen peroxide. Sections were then exposed to optimally diluted antisera to thyroglobulin (Dako Ltd), Thyroxine (T4) and Tri-iodothyronine (T3) (Miles-Yeda Ltd) followed by a standard peroxidase- $\mathbb{\mathbb { D }}$ antiperoxidase technique with diaminobenzidine $\frac{?}{\mathbb{D}}$ development. Trypsinisation was found to be unnec-o 908 
essary. Positive and negative controls were normal as were hyperplastic thyroid and non-thyroid tissue.

\section{ELECTRON MICROSCOPY}

Four oxyphil adenomas, two oxyphil carcinomas, and oxyphil change in one sample of Hashimoto's thyroiditis and one of papillary thyroid carcinoma were used. The specimens were postosmicated and routinely processed for electron microscopy. For immunoelectron microscopy three oxyphil adenomas were processed without osmication into London Resin white and immunostained for thyroglobulin, according to the protocol described by Newman and Jasani. ${ }^{9}$

\section{IMMUNOFLUORESCENCE}

Four oxyphil adenomas and oxyphil change in three colloid goitres, two cases of Graves' disease, and one Hashimoto's thyroiditis were used. Frozen sections were fixed briefly in acetone and exposed to optimally diluted rabbit fluorescein isothyiocynate conjugated antisera to immunoglobulins G, A, M, D, E, factor B, and complement components $\mathrm{C}_{3}$ and $\mathrm{C}_{4}$. After washing in phosphate buffered saline sections were mounted in glycerol-PBS and examined under ultraviolet microscopy.

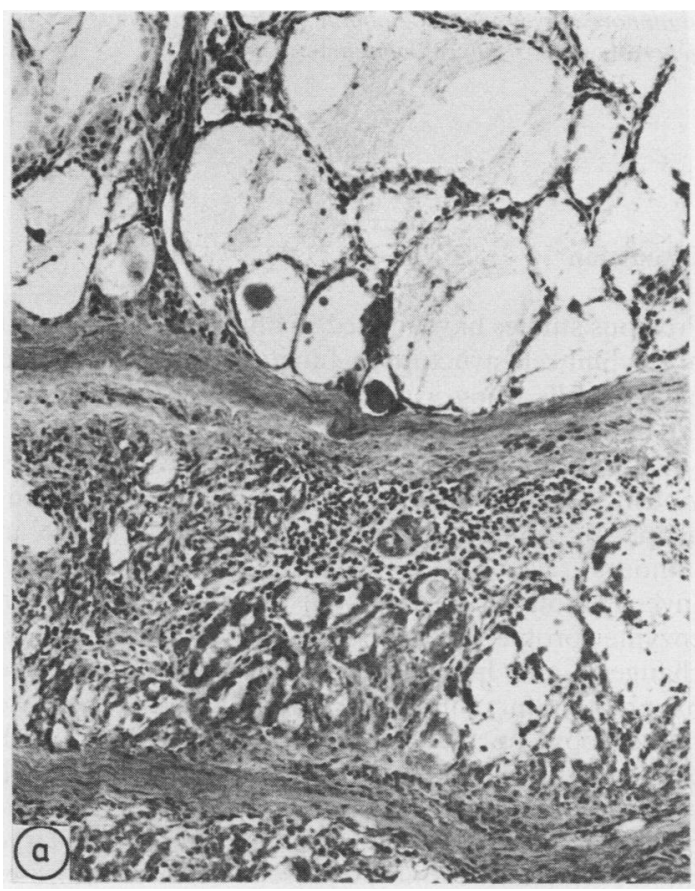

Fig. 1a Frozen section of colloid goitre. Oxyphil change in focal lymphocytic thyroiditis is seen (bottom) and non-oxyphil area (top). (Haematoxylin and eosin.) $\times 220$.

\section{Results}

\section{ENZYME REACTIONS}

The enzymes that gave a stronger reaction most consistently, (compared with normal thyroid) in oxyphil cells, were ICDH and SDH, and, to a lesser extent, HBDH and cytochrome oxidase. ICDH and SDH most easily identified focal oxyphil change as values of both were low in adjacent non-oxyphil cells (Figs. la and $b$ ). With minor variations, the activity of these enzymes was increased in all examples of oxyphil change, irrespective of whether they were associated with neoplastic or non-neoplastic conditions.

THYROGLOBULIN, T4, AND $\mathrm{T}_{3}$

In non-neoplastic oxyphil cells cytoplasmic staining of thyroglobulin was reduced compared with that of normal follicular cells. Similarly, oxyphil tumours showed generally weak reactivity but with focal accentuation. In oxyphil adenomas this accentuation was often seen in cells forming follicular structures (Fig. 2). Oxyphil carcinomas also contained sparse areas of focal reactivity. Colloid staining was variable but occasionally showed strong focal positivity. (Fig. 3). $T_{4}$ and $T_{3}$ immunoreactivity was limited to a small number of cells in occasional cases.

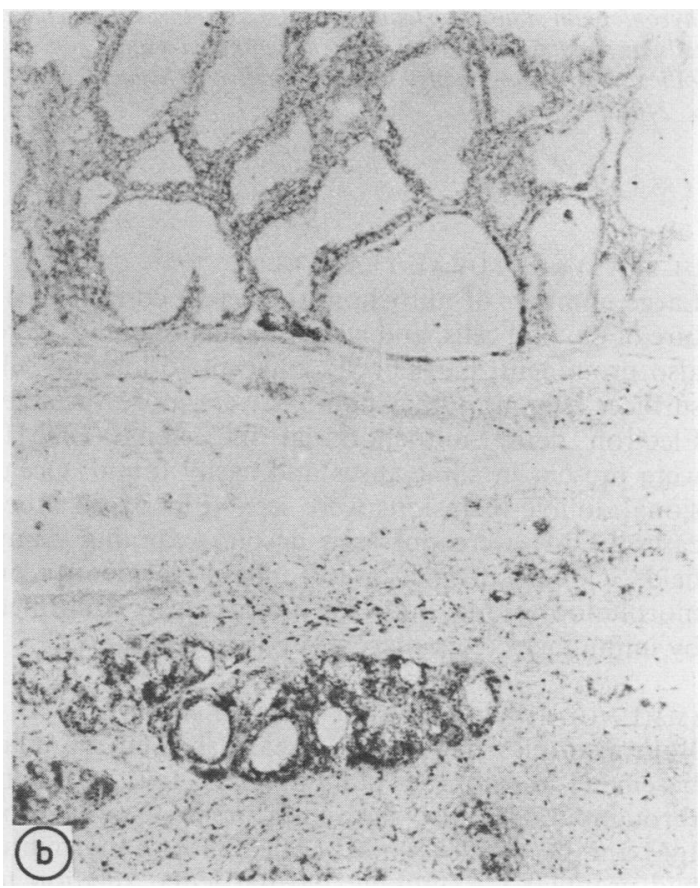

Fig. 1b Serial section stained for SDH showing increased intensity in area of oxyphil change. (Succinate dehydrogenase.) $\times 220$. 


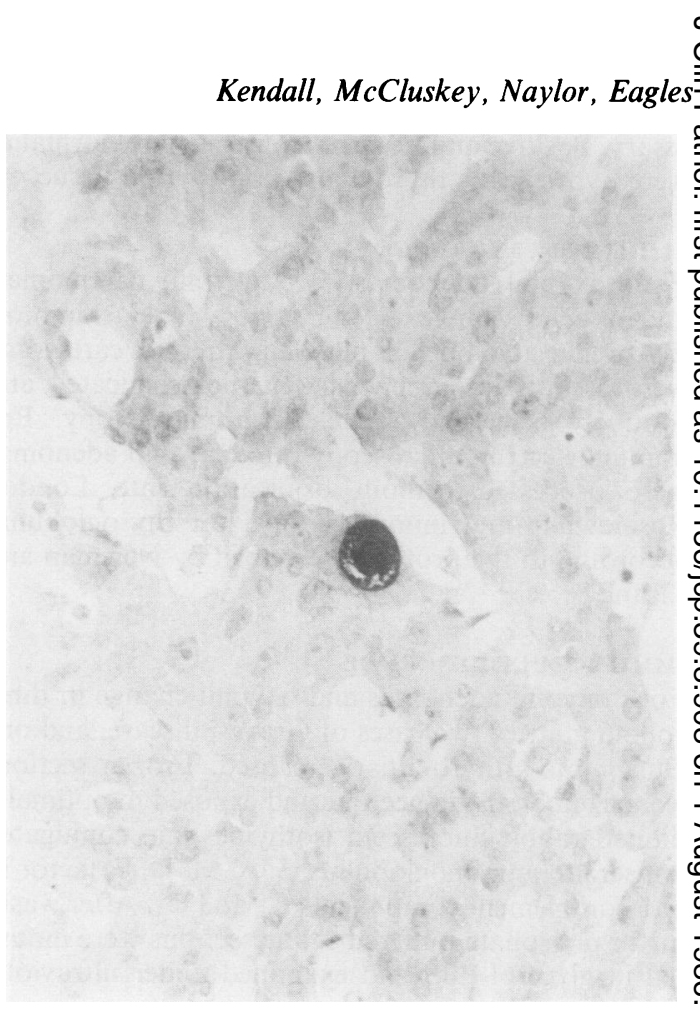

Fig. 2 Oxyphil adenoma showing accentuation of thyroglobulin staining around follicular structures. Elsewhere, cellular staining is minimal. Colloid contained within follicular structures is also immunoreactive (Thyroglobulin.) $\times 240$.

\section{ULTRASTRUCTURAL FEATURES}

Large numbers of mitochondria were a constant feature of oxyphil cells, and lysosomal dense bodies were also prominent, particularly adjacent to luminal cell surfaces (Fig. 4). Other findings were more variable. Electron dense mitochondrial inclusions (EDMI) were present in some cases and easily found. Occasional double inclusions were seen (Fig. 5). In other cases EDMI were not seen despite scanning many fields. Colloid droplets were difficult to identify on morphology alone, but their presence was confirmed by immunoelectron microscopy (Fig. 6).

\section{IMMUNOGLOBULINS AND COMPLEMENT}

Both examples of Graves' disease showed granular basement membrane staining for IgG diffusely throughout. One also showed prominent staining for IgM and $\mathrm{C}_{3}$. The example of Hashimoto's thyroiditis had granular $C_{3}$ staining. No particular relation to oxyphil areas could be determined. None of the four oxyphil adenomas or any of the three colloid goitres showed evidence of immune complex deposition.
Fig. 3 Oxyphil carcinoma showing microacinus strongly immunoreactive for thyroglobulin. Cellular staining is generally weak. (Thyroglobulin.) $\times 280$.

\section{Discussion}

Previous studies have tended to investigate one aspect: of oxyphil cell structure or function. We investigated 3 oxyphil cells using a multiple approach to correlate the findings.

High activities of oxidative enzymes have previously been shown in focal oxyphil change in nonneoplastic conditions, ${ }^{5610}$ but oxyphil change in $\frac{7}{0}$ tumours has been studied less extensively. Investigation of one oxyphil adenoma showed an $N$ enzyme profile similar to that of focal oxyphiln change, ${ }^{10}$ and homogenisation experiments on five oxyphil tumours found SDH and cytochrome oxidase $\omega$ raised above normal values ${ }^{2}$ Our results agreed with $<$ these findings, with a generally uniform profile in alle types of oxyphil change. The enzyme patterns observed are probably simply a reflection of the large numbers of mitochondria present as these enzymes are bound to the mitochondrial membrane.

Reports have differed regarding the synthetic abil- $-\frac{\Omega}{\mathbb{D}}$ ity of oxyphil cells. For thyroglobulin some have 


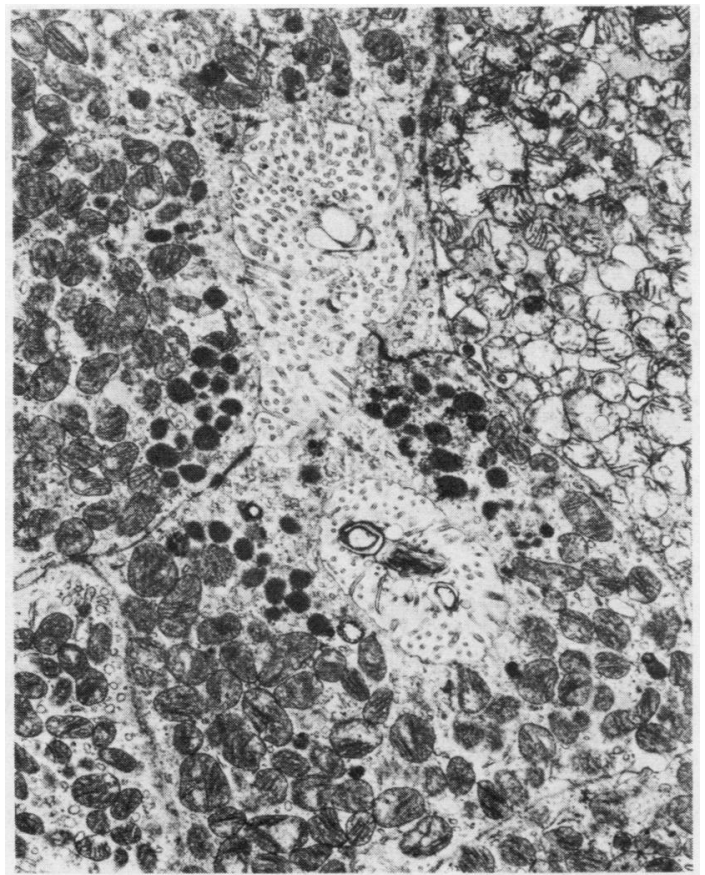

4

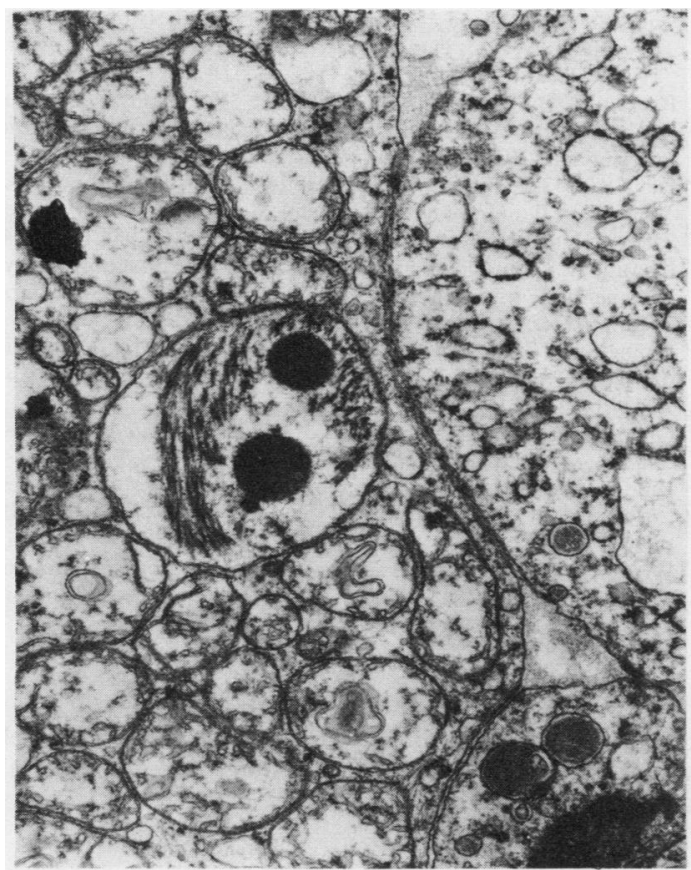

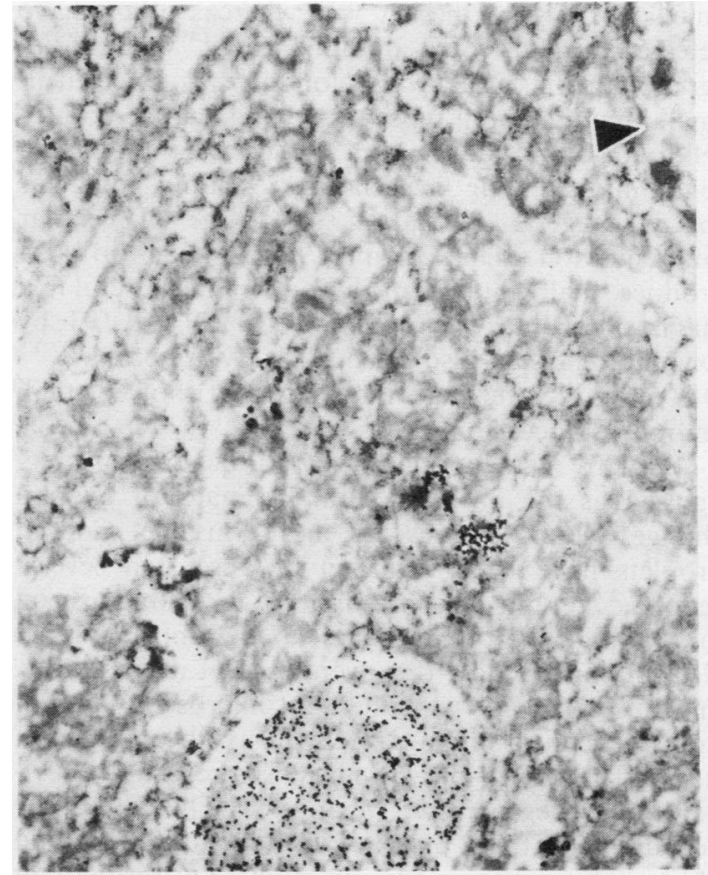

6

Fig. 4 Oxyphil adenoma with typically large numbers of mitochondria. Lysosomal dense bodies are also prominent adjacent to lumenal cell surface. (Uranyl acetate and lead citrate.) $\times 4500$.

Fig. 5 Oxyphil adenoma containing many Electron dense mitochondrial inclusions (EDMI), occasionally double as here. (Uranyl acetate and lead citrate.) $\times 15000$.

Fig. 6 Oxyphil adenoma immunostained for thyroglobulin. Strong reactivity is seen in intracytoplasmic colloid droplet. Part of cell nucleus is also seen (arrowhead). Colloid within follicular structures was similarly reactive. (Thyroglobulin.) $\times 12000$. 
failed to show synthesis, ${ }^{41112}$ whereas others have detected trace or small amounts. ${ }^{271314}$ Our studies agree with the latter: thyroglobulin was detected in small amounts in all types of oxyphil change both in cells and colloid. In tumours the accentuation of thyroglobulin staining in cells surrounding follicular spaces suggests a relation to degree of cellular differentiation. That oxyphil carcinomas do also produce small amounts of thyroglobulin is useful in a diagnostic context. Production of T4 and T3 by oxyphil cells has also been variably reported. ${ }^{4} 715$ Our findings agree with the study that showed small amounts in occasional cells. ${ }^{7}$

A greatly increased number of mitochondria is recognised as the ultrastructural hallmark of oxyphil change. Other features are more variable. Colloid droplets have been regarded as absent in several reports, ${ }^{2416}$ but they are difficult to distinguish on morphological grounds alone. On immunostaining at electron microscopy, they were present in our study, and this correlates with the light microscopy immunohistochemical findings. EDMI have been noted in tumours. ${ }^{216}$ Their presence has been regarded as evidence of degenerative change. ${ }^{17}$ This probably accounts for their presence in some tumours and absence from others in our study. Overgrowth of blood supply with relative ischaemia may be responsible.

Immune complex deposition has previously been shown in Graves' disease and Hashimoto's thyroiditis, ${ }^{1819}$ but oxyphil tumours have not apparently been investigated for this feature. The absence of immune complexes from oxyphil tumours suggests that immunological damage cannot be attributed to all types of oxyphil change.

In conclusion, the evidence from this study suggests that oxyphil change is uniform, with no detectable functional or structural differences in different conditions. As oxyphil change is found in various different disorders it is unlikely that only one pathogenetic pathway is entailed. It seems more probable that oxyphil change represents the common outcome from several different pathways. Investigation of thyroglobulin mRNA in oxyphil cells would be an additional interesting step to determine if high values of apparently available energy in oxyphil cells represent frustrated synthetic activity.

We thank Ms B Jordan for help with the photography, Janet Cope and PR Sanderson for additional technical help, Mrs GL Holmes and Mrs B Richardson for typing the manuscript, and Dr RA Walker for helpful comments. This project was supported by the Trent Regional Health Authority.

\section{References}

${ }^{1}$ Lennox B. The large cell small acinar thyroid tumour of Langhans and the incidence of related cell groups in the human thyroid. J Pathol Bacteriol 1948;60:295-305.

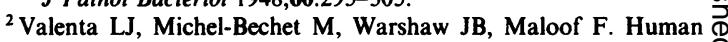
thyroid tumours composed of mitochondrion-rich cells: electron microscopic and biochemical findings. J Clin Endocrinol Metab o 1974;39:719-33.

${ }^{3}$ Feldman PS, Horvath E, Kovacs K. Ultrastructure of three Hurtle cell tumours of thyroid. Cancer 1972;30:1279-85.

${ }^{4}$ Heimann P, Ljunggren J-G, Lowhagen T, Hjern B. Oxyphilic ade- $\vec{\omega}$ noma of the human thyroid. A morphological and biochemical study. Cancer 1973;31:246-54.

${ }^{5}$ Tremblay G. Histochemical study of cytochrome oxidase and adenosine triphosphatase in Askanazy cells (Hurtle cells) of the human thyroid. Lab Invest 1962;11:514-7.

${ }^{6}$ Tremblay G, Pearse AGE. Histochemistry of oxidative enzyme systems in the human thyroid with special reference to Askanazy $\infty$ cells. J Pathol Bacteriol 1960;80:353-8.

${ }^{7}$ Kawaoi A, Okano T, Nemoto N, Shina Y, Shikata T. Simultaneous detection of thyroglobulin, thyroxine and triiodothyronine in non-toxic thyroid tumours by the immunoperoxidase method. Am J Pathol 1982;108:39-49.

${ }^{8}$ Lojda Z, Gossrau R, Schiebler TH. Enzyme histochemistry. $A \frac{\complement}{\oplus}$ Laboratory Manual. Berlin: Springer Verlag, 1979.

${ }^{9}$ Newman JR, Jasani B. In: Polak JM, Varndell IM. Postembedding immunoenzyme techniques eds. Immunolabelling for $\infty$ electron microscopy. Amsterdam: Elsevier, 1984.

${ }^{10}$ Harcourt-Webster JN, Stott NCH. Histochemical study of oxidative and hydrolytic enzymes in the human thyroid. $J$ Pathol Bacteriol 1966;92:291-302.

11 Valenta LJ, Michel-Bechet M. Ultrastructure and biochemistry of thyroid carcinoma. Cancer 1977;40:284-300.

12 Bocker W, Dralle H, Koch G, De Heer K, Hagemann J. Immu- D्Q nohistochemical and electron microscope analysis of adenomas $\overrightarrow{\bar{T}}$ of the thyroid gland. Virchows Arch (Pathol Anat) 윽 1978;380:205-20.

${ }^{13}$ Bocker W, Dralle H, Husselmann H, Bay V, Brassow M. Immu- ? nohistochemical analysis of thyroglobulin synthesis in thyroid carcinomas. Virchows Arch (Pathol Anat) 1980;385:187-200.

${ }^{14}$ De Keyser L, Layfield L, Van Herle A, Costin A, Lewin K. $\bar{O}$ Biochemical and immunohistochemical characterization of proteins in Hurtle cell carcinoma. J Endocrinol Invest 1984;7:449-54.

${ }^{15}$ Kawaoi A, Okano T, Nemoto N, Shikata T. Production of thyroxine and triiodothyronine in non-toxic thyroid tumours. Virchows Arch (Pathol Anat) 1981;390:249-57.

${ }^{16}$ Raffaele D, Kookmin MK. Dense core matrical mitochondrial 0 bodies in oncocytic adenoma of the thyroid. Arch Pathol Lab Med 1983;107:178-82.

${ }^{17}$ Ghadially FN. Mitochondria. Ultrastructural pathology of the cell and matrix. 2nd ed. London: Butterworths 238.

${ }^{18} \mathrm{~K}$ alderon AE, Boggars HA. Immune complex deposits in Graves' $\mathrm{N}$ disease and Hashimoto's thyroiditis. Am J Med 1977;63: 729-34.

${ }^{19}$ Werner SC, Wegelius O, Fierer JA, Hsu KC. Immunoglobulins and complement in the connective tissues of the thyroid in $\sigma$ Graves' disease. New Eng J Med 1972;287:421-5.

Requests for reprints to: Dr CH Kendall, Department of 7 Pathology, Clinical Sciences Building, Leicester Royal Infirmary, PO Box 65, Leicester LE2 7JX. 